\title{
Spatial abilities are not related to testosterone levels and variation in the androgen receptor in healthy young men
}

\author{
Aneta Kubranská ${ }^{1}$, Silvia Lakatošová ${ }^{1}$, Eva Schmidtová ${ }^{1}$, Jaroslava Durdiaková ${ }^{1,2}$, Peter Celec ${ }^{1,2,3}$ \\ and Daniela Ostatníková ${ }^{1}$ \\ ${ }^{1}$ Institute of Physiology, Faculty of Medicine, Comenius University, Bratislava, Slovak Republic \\ ${ }^{2}$ Institute of Molecular Biomedicine, Comenius University, Bratislava, Slovak Republic \\ ${ }^{3}$ Department of Molecular Biology, Comenius University, Bratislava, Slovak Republic
}

\begin{abstract}
Androgens modulate brain functions such as cognition, emotions and ability. Several studies have shown a correlation between testosterone levels and mental rotation. The aim of the present study was to confirm the influence of salivary testosterone levels, $2 \mathrm{D} / 4 \mathrm{D}$ ratio (such as a putative marker of prenatal testosterone), and sensitivity of androgen receptor on the mental rotation in healthy young men. Seventy-five healthy young men (age, 21.86 year) volunteered in this study. Mental rotation scores of our subjects were assessed using the Vandenberg and Kuse Mental Rotation Test. The 2D/4D finger length ratio as an indicator of prenatal testosterone was used as an average measurement of both hands. Correlation analysis revealed no correlation between salivary testosterone levels and mental rotation. However, we have observed a trend towards a negative correlation. There were no statistically significant results between $2 \mathrm{D} / 4 \mathrm{D}$ ratio and mental rotation or between polymorphic three-nucleotide (CAG) repeats and mental rotation tests. Future studies should focus on other genetic determinants of spatial abilities, potentially genes involved in testosterone metabolism.
\end{abstract}

Key words: Testosterone - Mental rotation - Androgen receptor - 2D/4D ratio

\section{Introduction}

There is compelling evidence that early androgen exposure is important for brain development and sexual differentiation in humans (Knickmeyer et al. 2011). There are two periods in early life during which the male brain is exposed to extremely high levels of androgens, during midgestation and during first few months of postnatal life (Beaton et al. 2011). Androgens modulate brain functions, such as cognition, emotions and behavior, that show sex differences, including sexual orientation, core gender identity, and some sex-related cognitive and personality characteristics (Hines et al. 2011).

Mental rotation (MRT) is the ability to imagine objects from a perspective other than the one depicted. Several studies have found a significant positive relationship between ac-

Correspondence to: Aneta Kubranská, Institute of Physiology, Faculty of Medicine, Comenius University, Bratislava, Slovak Republic

E-mail: aneta.kubranska@gmail.com tually measured testosterone levels and spatial ability scores (Silverman et al. 1999; Moffat et al. 2002; Hooven et al. 2004; Driscoll et al. 2005). Effects of testosterone supplementation on spatial memory have been also reported in healthy men (Cherrier et al. 2001). However, there are some studies that found no significant relationship between spatial skills and sex hormones (Bhasin et al. 2001; Fonda et al. 2005; Halari et al. 2005; Martin et al. 2008; Matousek and Sherwin 2010). Negative correlations between spatial skills and testosterone levels have been found by others (Ostatnikova et al. 2002; Yonker et al. 2006; Martin et al. 2007). Relationship between testosterone and spatial ability has also been studied in young adults. Puts et al. (2010) concluded that there is no consistent evidence that testosterone has activational effects on spatial ability. They did not find any significant association between testosterone levels and mental rotation in a large sample of young adults with an average age 22 . It was suggested that circulating testosterone does not predict mental rotation in young men, but its influence may be earlier, during the prenatal period (Puts et al. 2010). Organizational effect was supported by Heil et al. (2011) and Vuoksimaa et al. (2010). 
They studied females from the opposite-sex (OS) and twin pairs $v s$. females from the same-sex (SS). Data were fully consistent with the hypothesis that increased prenatal testosterone exposure in females masculinizes mental rotation performance with OS female twins having a higher mental rotation performance than SS female twins (Vuoksimaa et al. 2010; Heil et al. 2011). The organizational effect of testosterone is also supported by studies in patients with congenital adrenal hyperplasia $(\mathrm{CAH})$. Patients with $\mathrm{CAH}$ are consequently masculinized. Some studies have found $\mathrm{CAH}$ females to exhibit masculinized spatial abilities (Hines et al. 2003).

Androgens and estrogens differentially regulate the genes that control chondrocyte proliferation, leading to differential growth of the fourth digit in males and females (Zheng and Cohn 2011). Manning et al. (1998) introduced the length ratio of the second (index) finger to the fourth (ring) finger known as the 2D/4D ratio (Manning et al. 1998). High concentrations of fetal testosterone lead to a lower 2D/4D ratio, based on which it is assumed that there is increased prenatal testicular activity. The typical outcome is that high scores on a mental rotation test are associated with low values of the $2 \mathrm{D} / 4 \mathrm{D}$ ratio for males. The relationship between $2 \mathrm{D} / 4 \mathrm{D}$ and spatial ability has not been robustly demonstrated in previous studies. Significant associations have been reported between mental rotation accuracy and 2D/4D, particularly in men (Manning and Taylor 2001; McFadden and Shubel 2003). The effect of androgens is dependent not only on their current levels, but also on their metabolism. At the molecular level, the effect of androgens is mediated through the activation of androgen receptor (AR). A polymorphic three-nucleotide (CAG) repeats in exon 1 encodes a polyglutamic tract. The normal number of repeats is between 11 and 35 (Greenland and Zajac 2004). A reduced number is associated with higher AR transcriptional activity and, therefore, stronger androgen action (Tut et al. 1997). Several studies have shown that the number of CAG repeats directly correlates with serum testosterone levels, indicating that the weaker AR activity may indeed be compensated by higher androgen levels (Krithivas et al. 1999; Crabbe et al. 2007; Huhtaniemi et al. 2009).

The primary aim of our study was to confirm the influence of prenatal (such as 2D/4D ratio) and salivary testosterone levels and the sensitivity of androgen receptor on the mental rotation in healthy young men. We expected a negative correlation between salivary testosterone and mental rotation as found in our previous studies (Celec et al. 2002; Ostatnikova et al. 2010). As a secondary aim we investigated the influence of all measured parameters and their interaction on mental rotation performance. We also investigated the relationships between salivary testosterone levels and CAG repeats and $2 \mathrm{D} / 4 \mathrm{D}$ ratio and the relationship between CAG repeats and $2 \mathrm{D} / 4 \mathrm{D}$ ratio of both hands.

\section{Materials and Methods}

\section{Participants}

Seventy-five healthy young men age $21.86 \pm 1.65$ year (mean \pm SD) volunteered and provided written informed consent prior to their participation in this study. All volunteers were second year medical students at Comenius University in Bratislava. Exclusionary criteria were hormonal disorders in the subjects. All the participants were Caucasians and citizens of Slovakia. All procedures were approved by the Ethics Committee of the Comenius University Faculty of Medicine.

\section{Sample collection}

The probands were requested to collect whole saliva samples in a sterile tube (Sarstedt, Nümbrecht, Germany) between 8:00 and 10:00 am conforming to the circadian rhythm of testosterone. Volunteers were requested not to eat, drink or brush their teeth 30 minutes before the collection procedure.

\section{Genetic analyses}

Genomic DNA from saliva was extracted using the silica membrane based kit (Qiagen, Hilden, Germany) following the manufacturer's instructions (QIA amp DNA Blood Mini Kit Handbook 04/2010) according to DNA purification protocol for blood/body fluids.

Polymerase chain reaction (PCR) and electrophoresis were used to determine the number of microsatellite CAG repeats within Exon 1 of the Androgen Receptor gene ( $A R$ CAGn).

PCR was performed in $20 \mu \mathrm{l}$ volume with $250 \mathrm{nmol} / \mathrm{l}$ primers: forward: 5' GCGCGAAGTGATCCAGAAC 3' tagged with 6-carboxyfluorescein and reverse 5' CTCATCCAGGACCAGGTAGC 3', $1 \times$ Taq buffer (Fermentas, Vilnius, Lithuania) and $1 \mathrm{U}$ of Taq DNA polymerase (Fermentas, Vilnius, Lithuania). The PCR program included: initial denaturation at $94^{\circ} \mathrm{C}$ for $4 \mathrm{~min}$, followed by 35 cycles each consisting of denaturation at $94^{\circ} \mathrm{C}$ for $45 \mathrm{~s}$, annealing at $59.5^{\circ} \mathrm{C}$ for $45 \mathrm{~s}$ and polymerization at $72^{\circ} \mathrm{C}$ for $45 \mathrm{~s}$. The length of the final fragment was $181 \mathrm{bp}$. The number of repeats was analyzed by capillary electrophoresis.

\section{Hormonal analyses}

Testosterone levels were determined by ELISA assay using a commercial Salivary Testosterone ELISA kit according to the manufacturer's instructions (DRG Instruments $\mathrm{GmbH}$, Marburg, Germany). The intraassay coefficient of variation was $4.3 \%$ and interassay $7.2 \%$. 


\section{Measurement of $2 \mathrm{D} / 4 \mathrm{D}$ ratio}

Probands provided both hands to make a digital scan of the ventral surface. The lengths of second and fourth digit were measured and ratio was calculated using AutoMetric software in the left and right hand independently by two investigators and averaged.

\section{Spatial abilities}

An instrument widely used to assess the mental rotation test (MRT; Vandenberg and Kuse 1978), involves the comparison of 3D block figures. MRT was performed on all participants immediately after the collection of saliva in the morning between 8:00 to 10:00 am. This test measures one's capacity for mental manipulation and rotation of geometric shapes. Participants were provided with an image of a three-dimensional geometric object and asked to determine what the object would look like if it had been rotated in space choosing two correct responses from the four given possibilities for each item. If both marked figures were correct, participants were given one point, yielding a possible MRT score range from 0 to 20 . The MRT was administered in two parts (I and II), each consisting of 10 trials. Coefficient $K$ was calculated according to the formula: $K=\Psi^{2} /(\rho \times \omega)$; where $\Psi$ is the number of correct answers, $\rho$ is the number of answered trials and $\omega$ is the total number of trials. The time limit for each part was 3 minutes with a break between the two parts. There was 5-min practice period including four trials before the actual test.

\section{Statistical analyses}

For statistical analysis GraphPad Prism 5 was used. Data are presented in the form of a mean \pm SD. Linear correlation and linear regression analyses were conducted. Correlations of prenatal (assessed by 2D/4D ratio) and salivary testosterone levels with biological parameters were tested using the parametric Pearson's correlation test. Results of simple correlation between all variables are described by a correlation coefficient $(r)$. In form the results of linear regression showing the associations between biological parameters and mental rotation performance are described and shown as a coefficient of determination.

In addition, a multifactorial linear regression was used for the analysis of effects of the particular factors on MRT.

\section{Results}

Seventy-five healthy young men participated in this study, with average salivary testosterone levels of $0.599 \pm 0.263$ $\mathrm{nmol} / \mathrm{l}$ (Table 1). Average coefficient mental rotation scores
Table 1. Descriptive statistics of observed parameters in healthy young men

\begin{tabular}{|c|c|c|c|}
\hline \multicolumn{3}{|l|}{ Parameter } & Value \\
\hline \multicolumn{3}{|l|}{ Age (years) } & $21.860 \pm 1.650$ \\
\hline \multicolumn{3}{|c|}{ Testosterone level in saliva (nmol/l) } & $0.599 \pm 0.263$ \\
\hline \multicolumn{3}{|c|}{ Coefficient of mental rotation } & $0.383 \pm 0.208$ \\
\hline \multirow{6}{*}{$\begin{array}{l}\text { Raw score } \\
\text { of mental } \\
\text { rotation }\end{array}$} & \multirow{2}{*}{ correct answers } & part I & $4.884 \pm 2.118$ \\
\hline & & part II & $4.580 \pm 2.291$ \\
\hline & total correct answers & & $8.824 \pm 4.500$ \\
\hline & \multirow{2}{*}{ incorrect answers } & part I & $1.261 \pm 1.009$ \\
\hline & & part II & $1.826 \pm 1.350$ \\
\hline & total incorrect answers & & $2.878 \pm 1.951$ \\
\hline \multirow{3}{*}{$2 \mathrm{D} / 4 \mathrm{D}$ ratio } & right hand & & $0.979 \pm 0.035$ \\
\hline & left hand & & $0.975 \pm 0.033$ \\
\hline & averaged ratio & & $0.959 \pm 0.035$ \\
\hline \multicolumn{2}{|c|}{ (CAG)n (number or repeats) } & & $21.541 \pm 3.123$ \\
\hline
\end{tabular}

Value are mean \pm SD.

of our subjects were $0.383 \pm 0.208$ (Table 1 ). The average raw score of correct answers was $4.884 \pm 2.118$ in part I and $4.580 \pm 2.291$ in part II. The average raw score of incorrect answers was $1.261 \pm 1.009$ in part $I$ and $1.826 \pm 1.350$ in part II (Table 1). The average raw score of total correct and incorrect answers was $8.824 \pm 4.500$ and $2.878 \pm 1.951$ respectively.

Salivary testosterone levels did not correlate significantly with mental rotation $(r=-0.210, p=0.093$; Fig. 1A). However, we observed a trend toward negative correlation. We expected a negative correlation as in our previous studies (Celec et al. 2002; Ostatnikova et al. 2010). CAG repeats also did not correlate with mental rotation $(r=0.059, p=0.666$; Fig. 1B). These findings don't confirm the activational effect of testosterone, however, neither the organizational effect of testosterone. $2 \mathrm{D} / 4 \mathrm{D}$ ratio as a measure of prenatal level of androgens did not correlate with mental rotation in both hands, for the left hand $(r=-0.133, p=0.368)$, and for the right hand $(r=-0.115$, $p=0.441$; Fig. $1 \mathrm{C}$ and D).

Correlation analysis revealed no correlation between salivary testosterone levels and sensitivity of androgen receptor $(r=-0.044, p=0.735$; Fig. 2A). We expected that higher numbers of CAG repeats (weaker AR activity) will be compensated by higher testosterone levels, but the study did not confirm it. We also did not find any correlation between current and prenatal levels of testosterone. Salivary testosterone levels did not correlate with 2D/4D ratio in both hands: for the left hand $(r=0.018, p=0.902)$ and for the right hand ( $r=0.037, p=0.806$; Fig. $2 \mathrm{~B}$ and $\mathrm{C}$ ). Sensitivity of androgen receptor (CAG repeats) did not correlate neither, with $2 \mathrm{D} / 4 \mathrm{D}$ ratio in the left hand $(r=0.011$, 
A

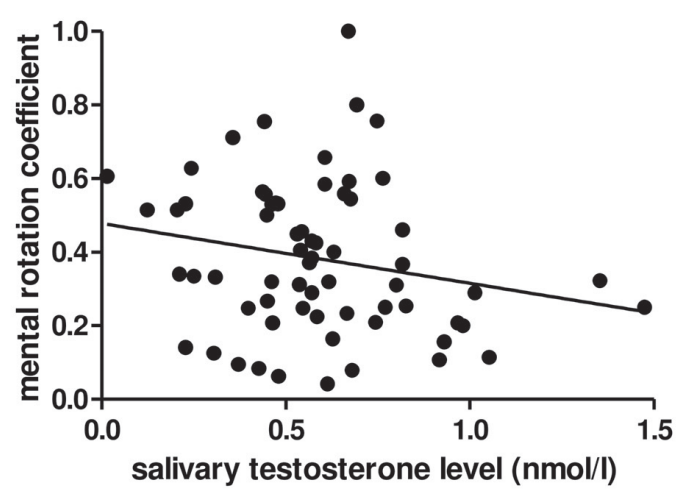

C

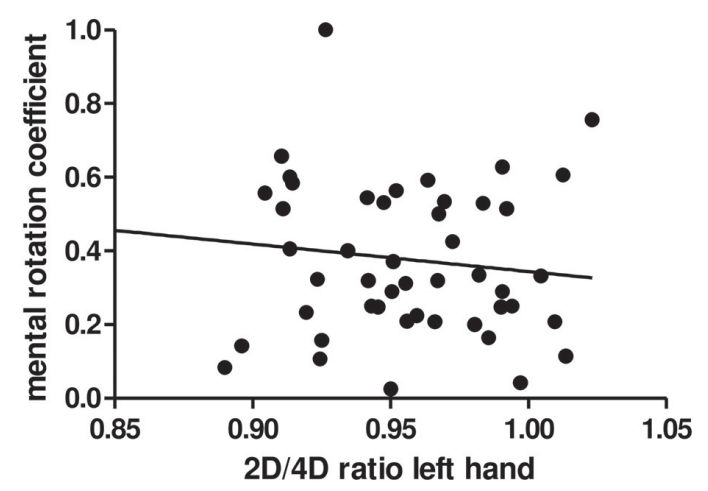

B

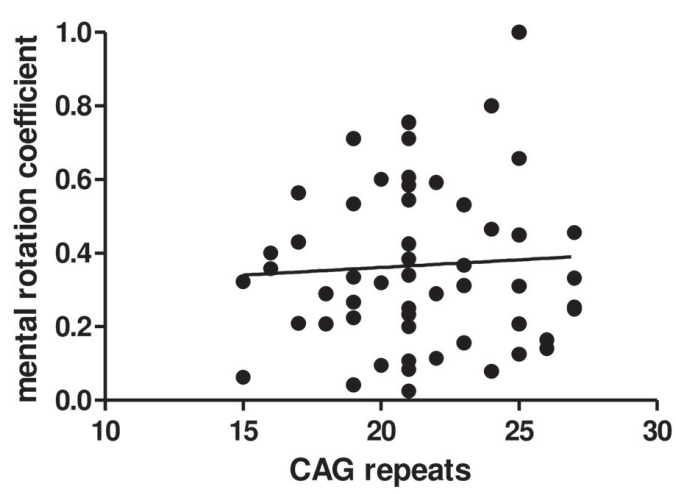

D

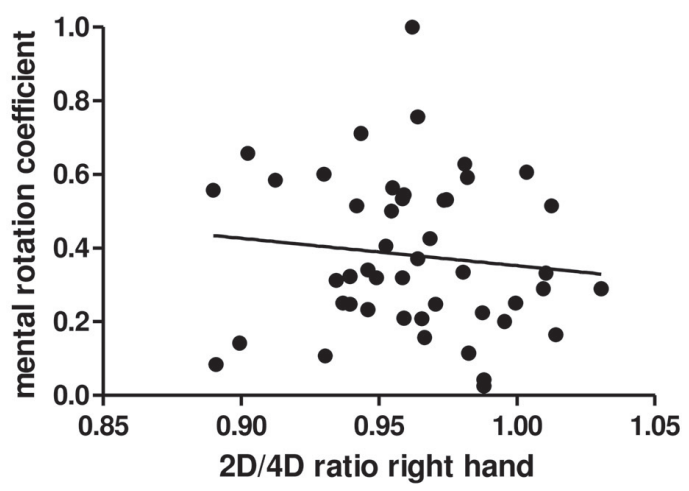

Figure 1. Correlation analysis between mental rotation coefficient and salivary testosterone levels and 2D/4D ratio and sensitivity of androgen receptor. A. Actual salivary testosterone levels did not correlate significantly with mental rotation $(r=-0.210, p=0.093)$. B. CAG repeats did not correlate with mental rotation $(r=0.059, p=0.666) .2 \mathrm{D} / 4 \mathrm{D}$ ratio such as retrospective correlate of androgens did not correlate with mental rotation in both hands, for the left hand $(r=-0.133, p=0.368 ; \mathbf{C})$, for the right hand $(r=-0.115, p=0.441 ; \mathbf{D})$.

$p=0.945$; Fig. 2D) and the right hand $(r=0.043, p=0.794$; Fig. 2E) respectively.

We have done linear model analysis testing what impact all measured parameters and their interaction have on MRT. The effect of actual salivary testosterone on MRT in multifactorial analysis was not significant $(\mathrm{F}=3.496$, $p=0.069)$. Similarly, excluding $2 \mathrm{D} / 4 \mathrm{D}$ from the interaction leads to no effect of salivary testosterone on MRT $(\mathrm{F}=1.844$, $p=0.180$ ). Exclusion of CAG repeats from the analysis led to a significant association between testosterone and MRT $(\mathrm{F}=4.938, p=0.031)$.

\section{Discussion}

This study was undertaken to examine the relationship between testosterone and mental rotation in a sample of 75 healthy young men. Contrary to our hypothesis, statistical analyses failed to reveal significant associations between salivary testosterone levels and performance of tasks for spatial abilities (Fig. 1A). In accordance with our study, Puts et al. (2010) also did not find a relationship between the salivary testosterone levels and mental rotation in young men (Puts et al. 2010). Based on these results we suspect that the effect of testosterone is earlier, during prenatal development. This organizational effect of testosterone is supported by Grimshaw et al. (1995), although their results are not entirely clear. Prenatal testosterone was measured from amniotic fluid between 14-20 weeks of pregnancy and children were tested at the age 7 . A significant positive association between fetal testosterone levels and faster performance on a mental rotation task was found in a subgroup of girls whose response times correlated with the angle of rotation, indicating they had used a rotational strategy (Grimshaw et al. 1995). However, there is also a finding by Auyeung et al. (2012), observing no significant relationship 
between mental rotation ability and fetal testosterone levels (Auyeung et al. 2012).

Opposite organizational effects of testosterone is an activational effect supported by studies that found relationship between actual levels of testosterone and spatial abilities (Thilers et al. 2006; Yonker et al. 2006; Martin et al. 2007; Hausmann et al. 2009). In the present study we expected that salivary testosterone levels will negatively correlate

A

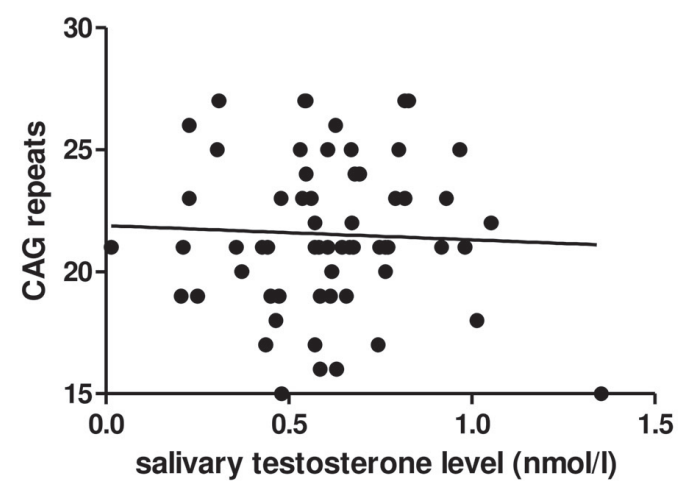

C

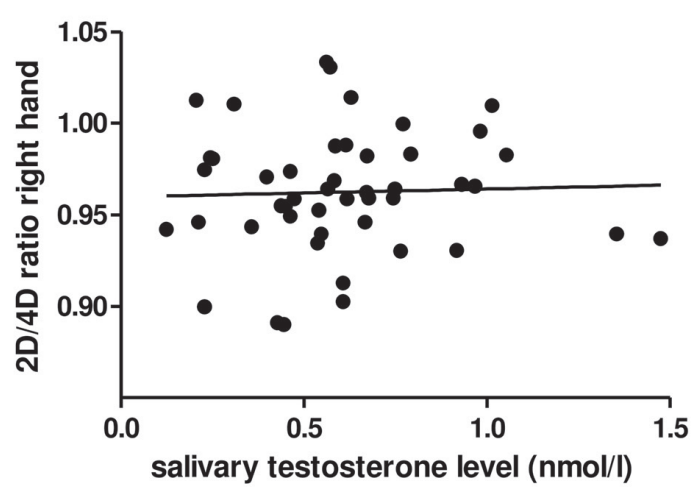

E

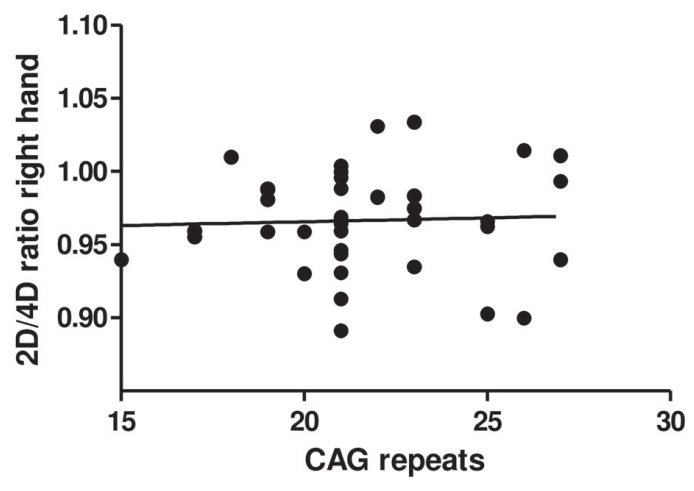

with mental rotation as in our previous studies (Celec et al. 2002; Ostatnikova et al. 2010) or in studies in young men (Moffat and Hampson 1996; Vuoksimaa et al. 2012). We have seen a trend towards a negative correlation, but we have not confirmed a predicted negative correlation probably due to the small number of subjects. Another possible explanation could be that testosterone influences cognition via its metabolites estradiol or dihydrotestosterone (Celec

B

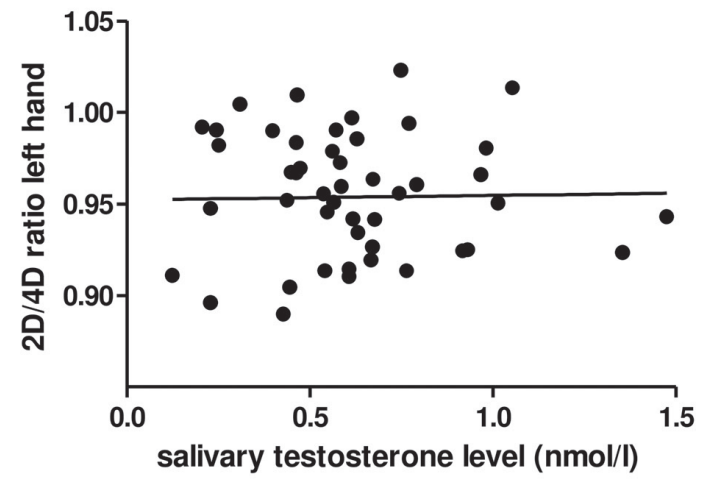

D

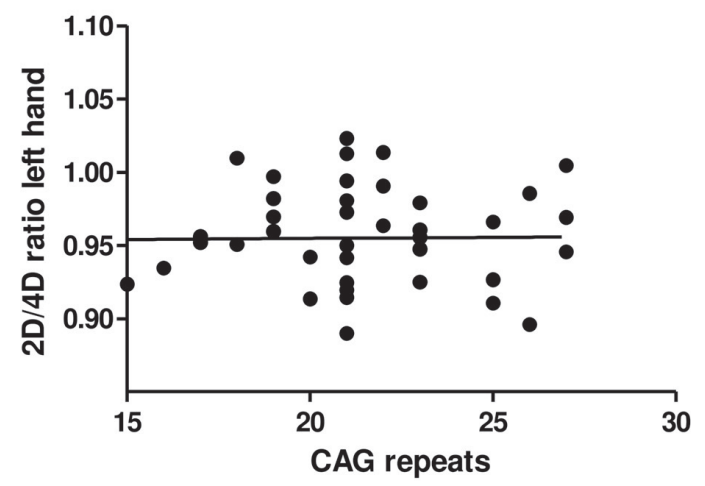

Figure 2. A. Correlation analysis revealed no correlation between actual salivary testosterone levels and sensitivity of androgen receptor $(r=-0.044, p=0.735)$. Salivary testosterone levels did not correlate with $2 \mathrm{D} / 4 \mathrm{D}$ ratio in both hands: for the left hand $(r=0.018, p=0.902 ; \mathbf{B})$ and for the right hand $(r=0.037, p=0.806$; C). Sensitivity of androgen receptor (CAG repeats) did not correlate neither with $2 \mathrm{D} / 4 \mathrm{D}$ ratio in the left hand $(r=0.011, p=0.945 ; \mathrm{D})$ nor the right hand $(r=0.043, p=0.794 ; \mathrm{E})$, respectively. 
et al. 2009; Kelemenova et al. 2010; Verhovshek et al. 2010). Ostatnikova et al. (2010) suggested that changes in spatial performance may depend on salivary testosterone fluctuations in both male and female subjects throughout a month, which would support the activational effects of currently circulating testosterone levels. Men achieved the best scores during the low-testosterone phase and women achieved the maximum score in the periovulatory phase (Celec et al. 2002; Ostatnikova et al. 2010). These findings support Courvoisier et al. (2013) in a longitudinal study, where the association between testosterone and performance differed across sexes (for males, it had an inverse U-shape, for females it was U-shaped) (Courvoisier et al. 2013). Abnormally high testosterone levels are linked with poor spatial ability. These results indicate that increasing testosterone levels do not necessarily lead to an amplification of male type characteristics. It seems that an optimal level of testosterone exists for certain cognitive domains (O'Connor et al. 2001).

The present study investigated the organizational effect of testosterone (through $2 \mathrm{D} / 4 \mathrm{D}$ ratio) on mental rotation. The typical outcome is that high scores on a mental rotation test are associated with low values of the 2D/4D ratio for males. Significant associations have been reported between mental rotation accuracy and $2 \mathrm{D} / 4 \mathrm{D}$, particularly in men (Manning and Taylor 2001; McFadden and Shubel 2003). Current results agree with papers where correlation was not found (Fig. 1C and D). The relationship between 2D/4D and visual-spatial cognition has not been clearly demonstrated in previous studies, possibly due to the differences in methodology, small samples sizes, and different ages of subjects. In the future, large sample studies are necessary to reveal associations between $2 \mathrm{D} / 4 \mathrm{D}$ ratio and spatial cognition that may bring significant and consistent results.

The effect of androgens is dependent not only on current levels, but also on their metabolism. Androgens act at the cellular level through the androgen receptor. Several studies documented a relationship between CAG polymorphism and cognitive abilities (Greenland et al. 2004). Lee and colleagues examined the association between cognition and AR CAG repeat length in older men. There was no correlation between CAG repeat length and fluid intelligence (Lee et al. 2010), which is consistent with our results (Fig. 1B). Our previous research indicated the association between functional polymorphism of the AR gene and intellectual giftedness in boys, but a number of CAG repeats was not correlated with any cognitive skills (Celec et al. 2013), however, authors revealed significant lower numbers of CAG repeats in gifted boys compared to controls. These results point towards a potential biological explanation of the relationship between testosterone and intelligence.

Previous studies focused on the relationship between testosterone levels and a number of CAG repeats. Several studies have shown that the number of CAG repeats directly correlated with serum testosterone levels, indicating that the weaker AR activity (longer CAG segment) may indeed be compensated by higher testosterone levels (Crabbe et al. 2007; Huhtaniemi et al. 2009). We have not found correlation between CAG repeats and testosterone levels (Fig. 2A). Apparent discrepancies between studies may be underlined by differences in population genetic background, and the age of enrolled men. There is one study in young men, which did not find significant association between testosterone levels and a number of CAG repeats (Canale et al. 2005). These and our results suggest that the current testosterone levels are independent of androgen receptor sensitivity. It would be useful to investigate several other polymorphisms in the gene for androgen receptor, which could affect the sensitivity of AR. The major limitation of our study is a relatively small sample size.

The relationship between $2 \mathrm{D} / 4 \mathrm{D}$ and fetal testosterone is clearly established. However, previous evidence of the relationship between the $2 \mathrm{D} / 4 \mathrm{D}$ ratio and adult testosterone values is controversial. Only García-Cruz et al. (2012) found negative correlation between $2 \mathrm{D} / 4 \mathrm{D}$ ratio with total, free, and bioavailable testosterone levels (Garcia-Cruz et al. 2012). However, this study was undertaken involving men with an average age 67 years. Nevertheless, our results are consistent with the results of studies of healthy young men (Fig. 2B and C). Studies of healthy young men did not find any relationship between their hormonal profile and 2D/4D relationship. The mean age of males was between 18-25 years in the normal population (Bang et al. 2005; Hönekopp et al. 2007).

Some studies have reported the relationship between (CAG)n in AR and 2D/4D ratio, Manning et al. (2003) first reported a correlation between the number of CAG repeats and $2 \mathrm{D} / 4 \mathrm{D}$ ratio (Manning et al. 2003). Low CAG repeats and a low $2 \mathrm{D} / 4 \mathrm{D}$ ratio indicate high activation of androgenresponsive genes. Marina et al. (2012) found positive correlation between CAG repeats and left hand digit ratio, with men with fewer CAG repeats having a significantly lower left hand 2D/4D ratio (Marina et al. 2012). We expected to find a positive correlation between $2 \mathrm{D} / 4 \mathrm{D}$ ratio and number of CAG repeats in our subjects. However, we were not able to prove our hypothesis. Thus, we cannot confirm the relationship between prenatal testosterone levels and androgen receptor sensitivity (Fig. 2D and E). Our results are in accordance with other studies which have not found a significant relationship between polymorphism in AR and 2D/4D ratio (Hurd et al. 2010; Folland et al. 2012). Further studies employing more subjects are needed to clarify these inconsistent findings.

This study had two aims. The first aim was to investigate the effects of prenatal (via 2D/4D ratio) and salivary testosterone levels or sensitivity of androgen receptor on mental rotation in young healthy men. As we expected we 
found that men with lower testosterone levels within the physiological range score better on tests of mental rotation, but these results were not statistically significant. Possible factors affecting our results were small sample size and also the fact that medical students are a group with highly specific interests, not representative of the general population and may affect their mental rotation ability. We assumed that mental rotation will also be affected by testosterone metabolism, but we were unable to demonstrate any effect. We have not found correlation between CAG repeats and testosterone levels. It is known that in the brain testosterone is converted to estradiol via aromatase. It is possible that decreased androgen sensitivity via a negative feedback mechanism indirectly affects estrogen receptor activation in some brain areas including those regions known to be important for spatial abilities. In the future it would be necessary to extend the analysis of genetic polymorphisms of the enzyme aromatase, which catalyzes the conversion of testosterone to estradiol.

A secondary objective of this study was to investigate the influence of all other variables and interaction between them on MRT performance. When we included all measured parameters the analysis, salivary testosterone levels had no effect on MRT performance. Similarly, the excluding 2D/4D from the interaction leads to no effect of salivary testosterone on MRT and the excluding a number of CAG repeats leads to significant effect of salivary testosterone on MRT. Taken together, it seems that testosterone partially determines MRT including its prenatal and actual salivary levels. Sensitivity of AR seems to influence salivary TST levels and thus may indirectly influence MRT performance.

In conclusion, our findings do not necessarily exclude the possible importance of the androgenic effect on the brain structure and function during the prenatal and postnatal period. These effects are shown in numerous studies showing that men score significantly better in tests of spatial skills than women. More studies that address the effects of androgens on specific cognitive abilities are needed to clarify this.

\section{Conclusion}

In healthy young men mental rotation is affected by neither the genetic polymorphisms of the androgen receptor nor by actual testosterone levels or $2 \mathrm{D} / 4 \mathrm{D}$ ratio reflecting prenatal testosterone levels. Future studies should focus on other genetic determinants of spatial abilities, potentially in genes involved in testosterone metabolism.

Acknowledgement. The study was supported by a grant: Building of Centre of Excellency for Sudden Cerebral Vascular Events, Comenius University Faculty of Medicine in Bratislava (ITMS: 26240120023), grant VEGA 1/0066/12.

\section{References}

Auyeung B., Knickmeyer R., Ashwin E., Taylor K., Hackett G., Baron-Cohen S. (2012): Effects of fetal testosterone on visuospatial ability. J. Arch Sex Behav. 41, 571-581 http://dx.doi.org/10.1007/s10508-011-9864-8

Bang A. K., Carlsen E., Holm M., Petersen J. H., Skakkebaek N. E., Jørgensen N. (2005): A study of finger lengths, semen quality and sex hormones in 360 young men from the general Danish population. J. Hum. Reprod. 20, 3109-3113 http://dx.doi.org/10.1093/humrep/deil70

Beaton A. A., Rudling N., Kissling C., Taurines R., Thome J. (2011): Digit ratio (2D:4D), salivary testosterone, and handedness. J. Laterality 16, 136-155

Bhasin S., Woodhouse L., Casaburi R., Singh A. B., Bhasin D., Berman N., Chen X., Yarasheski K. E., Magliano L., Dzekov C. et al. (2001): Testosterone dose-response relationships in healthy young men. J. Physiol. Endocrinol. Metab. 281, 1172-1181

Canale D., Caglieresi C., Moschini C., Liberati C. D., Macchia E., Pinchera A., Martino E. (2005): Androgen receptor polymorphism (CAG repeats) and androgenicity. J. Clin. Endocrinol. 63, 356-361 http://dx.doi.org/10.1111/j.1365-2265.2005.02354.x

Celec P., Ostatnikova D., Putz Z., Kudela M. (2002): The circalunar cycle of salivary testosterone and the visual-spatial performance. Bratisl. Lek. Listy 103, 59-69

Celec P., Ostatnikova D., Holesova Z., Minarik G., Ficek A., Kelemenova S., Putz Z., Kudela M. (2009): Spatial abilities in prepubertal intellectually gifted boys and genetic polymorphisms related to testosterone metabolism. J. Psychophysiol. 23, 1-6 http://dx.doi.org/10.1027/0269-8803.23.1.1

Celec P., Tretinarova D., Minarik G., Ficek A., Szemes T., Lakatosova S. (2013): Genetic polymorphisms related to testosterone metabolism in intellectually gifted boys. Plos One 8, 54751 http://dx.doi.org/10.1371/journal.pone.0054751

Cherrier M. M., Asthana S., Plymate S., Baker L., Matsumoto A. M., Peskind E., Raskind M. A., Brodkin K., Bremner W., Petrova A., LaTendresse S., Craft S. (2001): Testosterone supplementation improves spatial and verbal memory in healthy older men. J. Neurology 57, 80-88

Courvoisier D. S., Renaud O., Geiser C., Paschke K., Gaudy K., Jordan K. (2013): Sex hormones and mental rotation: an intensive longitudinal investigation. J. Horm. Behav. 63, 345-351 http://dx.doi.org/10.1016/j.yhbeh.2012.12.007

Crabbe P., Bogaert V., De Bacquer D., Goemaere S., Zmierczak H., Kaufman J. M. (2007): Part of the interindividual variation in serum testosterone levels in healthy men reflects differences in androgen sensitivity and feedback setpoint: contribution of the androgen receptor polyglutamine tract polymorphism. J. Clin. Endocrinol. Metab. 92, 3604-3610 http://dx.doi.org/10.1210/jc.2007-0117

Driscoll I., Hamilton D. A., Yeo R. A., Brooks W. M., Sutherland R. J. (2005): Virtual navigation in humans: the impact of age, sex, and hormones on place learning. J. Horm. Behav. 47, 326-335 http://dx.doi.org/10.1016/j.yhbeh.2004.11.013

Folland J. P., McCauley T. M., Phypers C., Hanson B., Mastana S. S. (2012): Relationship of 2D:4D finger ratio with muscle strength, 
testosterone, and androgen receptor CAG repeat genotype. Am. J. Phys. Anthropol. 148, 81-87 http://dx.doi.org/10.1002/ajpa.22044

Fonda S. J., Bertrand R., O'Donnell A., Longcope C., McKinlay J. B. (2005): Age, hormones, and cognitive functioning among middle-aged and elderly men: cross-sectional evidence from the Massachusetts male aging study. J. Gerontol. Biol. Sci. Med. Sci. 60, 385-390 http://dx.doi.org/10.1093/gerona/60.3.385

García-Cruz E., Huguet J., Piqueras M., Ribal M. J., Alcaraz A. (2012): Second to fourth digit ratio, adult testosterone level and testosterone deficiency. BJU Int. 109, 266-271 http://dx.doi.org/10.1111/j.1464-410X.2011.10249.x

Greenland J., Beilin J., Castro P. N., Varghese J. D., Zajac J. D. (2004): Polymorphic CAG repeat length in the androgen receptor gene and association with neurodegeneration in a heterozygous female carrier of Kennedy's disease. J. Neurol. 251, 35-41 http://dx.doi.org/10.1007/s00415-004-0266-x

Greenland K. J., Zajac J. D. (2004): Kennedy's disease: pathogenesis and clinical approaches. J. Intern. Med. 34, 279-286 http://dx.doi.org/10.1111/j.1444-0903.2004.00588.x

Grimshaw G. M., Sitarenios G.,Finegan J. A. K. (1995): Mental rotation at 7 years: relations with prenatal testosterone levels and spatial play experiences. Brain Cogn. 29, 85-100 http://dx.doi.org/10.1006/brcg.1995.1269

Halari R., Hines M., Kumari V., Mehrotra R., Wheeler M. Ng. V., Sharma T. (2005): Sex differences and individual differences in cognitive performance and their relationship to endogenous gonadal hormones and gonadotropins. J. Behav. Neurosci. 119, 104-117 http://dx.doi.org/10.1037/0735-7044.119.1.104

Hausmann M., Schoofs D., Rosenthal H. E., Jordan K. (2009): Interactive effects of sex hormones and gender stereotypes on cognitive sex differences--a psychobiosocial approach. Psychoneuroendocrinology 34, 389-401 http://dx.doi.org/10.1016/j.psyneuen.2008.09.019

Heil M., Kavšek M., Rolke B., Beste C., Jansen P. (2011): Mental rotation in female fraternal twins: Evidence for intra-uterine hormone transfer? J. Biol Psychol. 86, 90-93 http://dx.doi.org/10.1016/j.biopsycho.2010.11.002

Hines M., Fane B. A., Pasterski V. L., Mathews G. A., Conway G. S., Brook C. (2003): Spatial abilities following prenatal androgen abnormality: Targeting and mental rotations performance in individuals with congenital adrenal hyperplasia. Psychoneuroendocrinology $\mathbf{2 8 ,}, 1010-1026$ http://dx.doi.org/10.1016/S0306-4530(02)00121-X

Hönekopp J., Bartholdt L., Beier L., Liebert A. (2007): Second to fourth digit length ratio (2D:4D) and adult sex hormone levels: new data and a meta-analytic review. Psychoneuroendocrinology 32, 313-321

http://dx.doi.org/10.1016/j.psyneuen.2007.01.007

Hooven C. K., Chabris C. F., Ellison P. T., Kosslyn S. M. (2004): The relationship of male testosterone to components of mental rotation. Neuropsychologia 42, 782-790 http://dx.doi.org/10.1016/j.neuropsychologia.2003.11.012

Huhtaniemi I. T., Pye S. R., Limer K. L., Thomson W., O'Neill T. W., Platt H., Payne D., John S. L., Jiang M., Boonen S. et al. and European Male Ageing Study Group (2009): Increased estrogen rather than decreased androgen action is associated with longer androgen receptor CAG repeats. J. Clin. Endocrinol. Metab. 94, 277-284

http://dx.doi.org/10.1210/jc.2008-0848

Hurd P. L., Vaillancourt K. L., Dinsdale N. L. (2010): Aggression, digit ratio and variation in androgen receptor and monoamine oxidase a genes in men. J. Behav. Genet. 41, 543-556 http://dx.doi.org/10.1007/s10519-010-9404-7

Kelemenova S., Schmidtova E., Ficek A., Celec P., Kubranska A., Ostatnikova D. (2010): Polymorphisms of candidate genes in Slovak autistic patients. Psychiatr. Genet. 20, 137-139 http://dx.doi.org/10.1097/YPG.0b013e32833a1eb3

Knickmeyer R. C., Woolson S., Hamer R. M., Konneker T., Gilmore J. H. (2011): 2D:4D ratios in the first 2 years of life: Stability and relation to testosterone exposure and sensitivity. Horm. Behav. 60, 256-263 http://dx.doi.org/10.1016/j.yhbeh.2011.05.009

Krithivas K., Yurgalevitch S. M., Mohr B. A., Wilcox C. J., Batter S. J., Brown M., Longcope C., McKinlay J. B., Kantoff P. W. (1999): Evidence that the CAG repeat in the androgen receptor gene is associated with the age-related decline in serum androgen levels in men. J. Endocrinol. 162, 137-142 http://dx.doi.org/10.1677/joe.0.1620137

Lee D. E., Ulubaev A., Tajar A., Pye S. R., Pendleton N., Purandare N. (2010): Endogenous hormones, androgen receptor CAG repeat length and fluid cognition in middle-aged and older men: Results from the European Male Ageing Study. Eur. J. Endocrinol. 162, 1155-1164 http://dx.doi.org/10.1530/EJE-09-0970

Manning J. T., Scutt D., Wilson J., Lewis-Jones D. I. (1998): The ratio of 2 nd to 4 th digit length: a predictor of sperm numbers and concentrations of testosterone, luteinizing hormone and oestrogen. J. Hum. Reprod. 13, 3000-3004

http://dx.doi.org/10.1093/humrep/13.11.3000

Manning J. T., Taylor R. P. (2001): Second to fourth digit ratio and male ability in sport: Implications for sexual selection in humans. Evol. Hum. Behav. 22, 61-69 http://dx.doi.org/10.1016/S1090-5138(00)00063-5

Manning J. T., Bundred P. E., Newton D. J., Flanagan B. F. (2003): The second to the fourth digit ratio and variation in the androgen receptor gene. Evol. Hum. Behav. 24, 399-405 http://dx.doi.org/10.1016/S1090-5138(03)00052-7

Marina L., Butovskaya Vasiliy A., Vasilyev Oleg E. L., Valentina N. B., Alex M. K., Audax M., Dmitriy V. S., Alexey P. R. (2012): Aggression, digit ratio, and variation in the androgen receptor, serotonin transporter, and dopamine D4 receptor genes in African Foragers: The Hadza. Behav. Genet. 42, 647-662 http://dx.doi.org/10.1007/s10519-012-9533-2

Martin D. M., Wittert G., Burns N. R., Haren M. T., Sugarman R. (2007): Testosterone and cognitive function in ageing men: data from the Florey Adelaide Male Ageing Study (FAMAS). Maturitas 57, 182-194 http://dx.doi.org/10.1016/j.maturitas.2006.12.007

Martin D. M., Wittert G., Burns N. R., McPherson J. (2008): Endogenous testosterone levels, mental rotation performance, and constituent abilities in middle-to-older aged men. Horm. Behav. 53, 431-441 http://dx.doi.org/10.1016/j.yhbeh.2007.11.012 
Matousek R. H, Sherwin B. B. (2010): Sex steroid hormones and cognitive functioning in healthy, older men. Horm. Behav. 57, 352-359 http://dx.doi.org/10.1016/j.yhbeh.2010.01.004

McFadden D., Shubel E. (2003): Relative lengths of fingers and toes in human malesand females. Horm. Behav. 42, 492-500 http://dx.doi.org/10.1006/hbeh.2002.1833

Moffat S. D., Zonderman A. B., Metter E. J., Blackman M. R., Harman S. M., Resnick S. M. (2002): Longitudinal assessment of serum free testosterone concentration predicts memory performance and cognitive status in elderly men. J. Clin. Endocrinol. Metab. 87, 5001-5007 http://dx.doi.org/10.1210/jc.2002-020419

Moffat S. D., Hampson E. (1996): A curvilinear relationship between testosterone and spatial cognition in humans: possible influence of hand preference. Psychoneuroendocrinology 21, 323-337 http://dx.doi.org/10.1016/0306-4530(95)00051-8

O‘Connor D. B., Archer J., Hair W. M., Wu F. C. (2001): Activational effects of testosterone on cognitive function in men. Neuropsychologia 39, 1385-1394 http://dx.doi.org/10.1016/S0028-3932(01)00067-7

Ostatnikova D., Putz Z., Celec P., Hodosy J. (2002): May testosterone levels and their fluctuations influence cognitive performance in humans? Scripta Medica 75, 245-254

Ostatnikova D., Hodosy J., Skoknova M., Putz Z., Kudela M., Celec P. (2010): Spatial abilities during the circalunar cycle in both sexes. J. Learn. Individ. Differ. 20, 484-487 http://dx.doi.org/10.1016/j.lindif.2010.05.004

Puts D. A., Cardenas R. A., Bailey D. H., Burriss R. P., Jordan C. L., Breedlove S. M. (2010): Salivary testosterone does not predict mental rotation performance in men or women. Horm. Behav. 58, 282-289 http://dx.doi.org/10.1016/j.yhbeh.2010.03.005

Silverman I., Kastuk D., Choi J., Phillips K. (1999): Testosterone levels and spatial ability in men. Psychoneuroendocrinology 24, 813-822 http://dx.doi.org/10.1016/S0306-4530(99)00031-1
Thilers P. P., MacDonald S. W. S., Herlitz A. (2006): The association between endogenous free testosterone and cognitive performance: a population-based study in 35 to 90 year-old men and women. Psychoneuroendocrinology 31, 565-576 http://dx.doi.org/10.1016/j.psyneuen.2005.12.005

Tut T. G., Ghadessy F. J., Trifiro M. A., Pinsky L., Yong E. L. (1997): Long polyglutamine tracts in the androgen receptor are associated with reduced trans-activation, impaired sperm production, and male infertility. J. Clin. Endocrinol. Metab. 82, 3777-3782

Vandenberg S. G., Kuse A. R. (1978): Mental rotations, a group test of threedimensional spatial visualization. Percept. Mot. Skills 47, 599-604 http://dx.doi.org/10.2466/pms.1978.47.2.599

Verhovshek T., Buckley K. E., Sergent M. A., Sengelaub D. R. (2010): Testosterone metabolites differentially maintain adult morphology in a sexually dimorphic neuromuscular system. Dev. Neurobiol. 70, 206-221 http://dx.doi.org/10.1002/dneu.20780

Vuoksimaa E., Kaprio J., Kremen W. S., Hokkanen L., Viken R. J., Tuulio-Henriksson A., Rose R. J. (2010): Having a male co-twin masculinizes mental rotation performance in females. Psychol. Sci. 21, 1069-1071 http://dx.doi.org/10.1177/0956797610376075

Vuoksimaaa E., Kaprioa J., Erikssona P. C. J., Rosea R. J. (2012): Pubertal testosterone predicts mental rotation performance of young adult males. Psychoneuroendocrinology 37, 1791-1800 http://dx.doi.org/10.1016/j.psyneuen.2012.03.013

Yonker J. E., Eriksson E., Nilsson L. G., Herlitz A. (2006): Negative association of testosterone on spatial visualization in 35 to 80 year old men. Cortex 42, 376-386 http://dx.doi.org/10.1016/S0010-9452(08)70364-2

Zheng Z., Cohn M. J. (2011): Developmental basis of sexually dimorphic digit ratios. Proc. Natl. Acad. Sci. U. S. A. 108, 16289-16294 http://dx.doi.org/10.1073/pnas.1108312108

Received: September 16, 2013

Final version accepted: January 14, 2014 